\title{
Abordagem social do conhecimento
}

\section{Social approach to knowledge}

DOI: 10.46814/lajdv2n4-004

Recebimento dos originais: 10/04/2020

Aceitação para publicação: 10/04/2020

\author{
Adelcio Machado dos Santos \\ Pós-Doutor em Gestão do Conhecimento pela UFSC \\ Instituição: Universidade Alto Vale do Rio do Peixe (UNIARP) \\ Endereço: Rua Prof. Egídio Ferreira, nº 271, Capoeiras/Florianópolis/SC/Brasil \\ E-mail: adelciomachado@gmail.com
}

\section{RESUMO}

Ao longo da história, os conhecimentos foram sendo produzidos não de forma cumulativa, mas de maneira dinâmica, com ressignificações sucessivas em busca das representações viáveis e coerentes com o mundo das experiências humanas. De acordo com Moretto (2003), essa construção ao longo da história humana nem sempre se deu de forma pacífica. Na realidade, ocorreu em meio a contradições sociais, com superação de vaidades, com frustrações individuais e com a contribuição de muitos estudiosos persistentes que perseguiram firmemente seus ideais, posto que arcando com ônus por suas idéias inovadoras.

Palavras-chave: Conhecimento, Sociabilidade, Inovação.

\section{ABSTRACT}

Throughout history, knowledge has been produced not cumulatively, but dynamically, with successive reframings in search of viable representations that are consistent with the world of human experiences. According to Moretto (2003), this construction throughout human history has not always taken place in a peaceful way. In reality, it occurred in the midst of social contradictions, overcoming vanities, with individual frustrations and with the contribution of many persistent scholars who firmly pursued their ideals, since they bear the burden of their innovative ideas.

Keywords: Knowledge, Sociability, Innovation.

\section{INTRODUÇÃO}

Em primeiro lugar, configura-se patente que todo conhecimento constitui produção social e, por conseguinte, conjunto de verdades relativas que se transformam em função do desenvolvimento das sociedades e dos recursos tecnológicos disponíveis. Um indivíduo que vem ao mundo encontra uma realidade já construída, ou seja, um conjunto de conhecimentos estabelecidos, estruturados, institucionalizados e legitimados.

Este conjunto de conhecimentos tem como objetivo dar um sentido às experiências vividas pelos homens e constitui a realidade objetiva da sociedade onde o indivíduo viverá. 
Por conseguinte, a socialização primária corresponde ao período o qual o indivíduo se torna membro de uma sociedade por intermédio do acesso aos primeiros elementos do universo simbólico dessa mesma sociedade da qual ele será membro.

De acordo com o magistério de Moretto (2003), os primeiros elementos são transmitidos pela educação em família. Esta educação transmite ao humano na infância os conhecimentos indispensáveis para começar a construir a realidade subjetiva que lhe permitirá viver dialeticamente com uma realidade objetiva pela sociedade.

A socialização secundária corresponde a um período em que o indivíduo se conscientiza da complexidade cada vez maior da realidade social e da divisão do trabalho.

Este fato o levará a compreender a distribuição social dos conhecimentos em função da distribuição do labor.

\section{DESENVOLVIMENTO}

Ele se conscientizará de que, em toda sociedade, uns têm o conhecimento necessário para serem médicos, outros para serem engenheiros, advogados, professores, e assim sucessivamente.

Ainda à luz da preleção da lavra de Moretto (2003), um indivíduo não pode ter todos os conhecimentos, e não pode desempenhar todas as funções na sociedade porque funções diferentes exigem e determinam conhecimentos diferentes.

Uma vez que os conhecimentos são construídos, institucionalizados e legitimados socialmente para dar sentido às experiências vividas por indivíduos de certa sociedade, pode-se imaginar que novas experiências permitirão a construção de novos conhecimentos, os quais serão instituídos e legitimados pelas novas gerações.

Ademais, os conhecimentos não são uma descrição da realidade dada, mas uma representação que dela é construída, construção cuja função é adaptativa, isto é, permite ao indivíduo prever as regularidades e assim viver num mundo de limitações, representado pelo mundo das coisas.

Diz respeito, exclusivamente, à classificação e à organização de um mundo constituído pela experiência humana, isto é, pelas relações que são estabelecidas nos resultados dos experimentos que o indivíduo faz ao longo de sua interação com o mundo dos objetos que lhe rodeiam.

O conhecimento e as informações de modo geral se transformaram nos principais recursos econômicos para a competitividade das empresas, fazendo com que emergisse uma necessidade de valorização, mantença e desenvolvimento nas organizações de forma completa e estruturada. 
Consoante explica Ponchirolli (2005) $)^{1}$, que as organizações se encontram no limiar de uma nova era, na qual se reconhece o conhecimento como um dos ativos mais relevantes das organizações, constituindo-se como a chave para a vantagem competitiva sustentável.

Destarte, a fonte das riquezas empresariais e da competitividade, que, até agora, era fortemente caracterizada pelos bens tangíveis - capital financeiro, estruturas físicas - passa a ser o próprio conhecimento.

Destarte, a Gestão do Conhecimento nas organizações torna-se instrumento essencial para que uma organização assegure sua sobrevivência em longo termo. Figueiredo (2005) ${ }^{2}$ esclarece que a Gestão do Conhecimento emergiu para que as empresas encontrem as melhores maneiras de mobilizar e alavancar o conhecimento individual, para que este possa se tornar parte integrante da estrutura organizacional.

De acordo com o magistério de Siqueira (2005), a Gestão do Conhecimento se faz cada vez mais presente dentro das organizações contemporâneas.

$\mathrm{Na}$ atualidade, a necessidade de as organizações criarem e manterem modelos e processos que transformem conhecimento em vantagem competitiva se configura inquestionável. A maior parte das organizações já identificou a relevância de criar, adquirir e transferir conhecimento, incrementando os novos comportamentos e idéias inovadoras

Ponchirolli (2005), outrossim, aclara que a ênfase no conhecimento pressupõe a necessidade de sua gestão.

Nesse sentido, a criação de um ambiente organizacional pautado na Gestão do Conhecimento suscita a necessidade de uma sinergia constante entre três dimensões organizacionais, quais sejam: infraestrutura, pessoas e tecnologia. Dessa maneira, o investimento efetuado por uma organização na gestão do conhecimento se traduz na busca pela obtenção da harmonia e coerência entre as variáveis que formam essas dimensões.

A dimensão da infraestrutura busca a criação de um ambiente adequado ao desenvolvimento da gestão do conhecimento, englobando variáveis como estrutura organizacional, estilo gerencial, cultura organizacional e visão holística. (PONCHIROLLI, 2005).

Já a dimensão pessoas é caracterizada pela busca da aprendizagem permanente, pelo incentivo à criatividade, à inovação e ao compartilhamento do conhecimento, valorizando-se a intuição.

\footnotetext{
${ }^{1}$ PONCHIROLLI, Osmar. Capital humano: sua importância na gestão estratégica do conhecimento. Curitiba: Juruá, 2005.

${ }^{2}$ FIGUEIREDO, Saulo Porfírio. Gestão do conhecimento: estratégias competitivas para a criação e mobilização do conhecimento na empresa. São Paulo: Qualitymark, 2005.
} 
Ademais, incentiva-se a consciência da existência e da necessidade de se trabalhar modelos mentais, assim como viabilizar o seu descobrimento.

Por sua vez, a dimensão tecnológica compreende o suporte da tecnologia às atividades relacionadas à gestão do conhecimento. Estão incluídas aqui as redes de computadores (Internet, intranet e extranet), Gerenciamento Eletrônico de Documentos (GED), datawarehouse, entre outras ferramentas que apoiam de modo decisivo o gerenciamento do conhecimento na organização.

Em última análise, no âmbito do contexto organizacional, ademais ensejar o manejo das informações existentes, o processo de gestão do conhecimento, corretamente estruturado, envolve a geração, a codificação e o compartilhamento do conhecimento dentro da empresa.

Acerca dessas diversas funcionalidades da Gestão do Conhecimento, Ponchirolli (2005, p. 80) exara que

\begin{abstract}
a geração do conhecimento refere-se a todas as formas de criação do conhecimento, seja a partir da interação com o ambiente externo, ou, até mesmo, da interação entre os indivíduos da organização. A codificação tem como objetivo identificar e estruturar os conhecimentos úteis para a organização, de forma a torná-los acessíveis àqueles que dele precisam. $\mathrm{O}$ compartilhamento corresponde à transferência do conhecimento, seja esta espontânea (informal) ou estruturada (formal), entre os membros da organização.
\end{abstract}

Em abordagem ontológica, a Gestão do Conhecimento no seio das organizações pode também consistir em ação sistemática responsável por transformar patrimônio intelectual da organização em maior produtividade, novos valores e aumento de competitividade, com a função de apoiar e orientar a melhor forma de capitalizar o conhecimento organizacional.

A Gestão do Conhecimento orienta o patrimônio intelectual da organização, almejando a obtenção de melhores resultados em termos de produtividade e capacidade de inovação.

É um processo que inclui geração, coleta, assimilação e aproveitamento do conhecimento, de forma a aumentar a sua inteligência e competitividade. (SIQUEIRA, 2005) ${ }^{3}$.

Sob essa perspectiva, valoriza-se o compartilhamento das informações, fundamental para que a informação seja assimilada enquanto conhecimento. É preciso desenvolver uma visão pautada no conhecimento dos processos de negócio, objetivando maximizar a capacidade de processamento de informações avançadas.

É importante ocupar o ambiente físico da organização com idéias, divulgando sabedorias e explorando as formas mais evoluídas de sistemas e tecnologias. A transformação da informação em práxis, por intermédio da criatividade e inovação dos seres humanos, terminará por afetar a competência da organização.

\footnotetext{
${ }^{3}$ SIQUEIRA, Marcelo Costa. Gestão estratégica da informação: como transformar o conteúdo informacional em conhecimento valioso. Rio de Janeiro: Brasport, 2005.
} 
Torna-se claro que os conhecimentos não têm o objetivo de descrever uma realidade ontológica, isto é, como ela seria em si mesma, mas dar sentido às experiências que o sujeito realiza em um mundo de limitações.

A Sociologia do Conhecimento não lida com os problemas filosóficos do conhecimento, objeto da gnosiologia. E ao próprio conceito do conhecimento dá uma amplitude maior, fazendo-se abranger todo o espectro dos produtos culturais.

Na primeira metade do século XX, a Sociologia do Conhecimento começa a se apresentar como tal e a ser sistematizada. Só então é que ela ganha status universitário (BERTELLI; PALMEIRA; VELHO, 1974).

Em vez de se preocupar com o conhecimento em si mesmo, esta disciplina centra o seu interesse no estudo das relações entre o conhecimento e o contexto social em que ele acontece.

Sustenta que os modos de pensar e de conhecer dependem da realidade social em que se formam, ou, mais precisamente: dos grupos sociais a que pertencem os indivíduos.

Se ela analisa as relações entre conhecimento e existência, como pesquisa históricosociológica busca revelar as formas que aquelas relações assumem.

Encontrar critérios que permitam ao homem determinar as conexões entre pensamento e ação, e desenvolver uma teoria sobre a significação dos fatores não-teóricos que condicionam o conhecimento são as preocupações fundamentais da sociologia do conhecimento.

A relação de correspondência entre a estrutura socioeconômica e os produtos culturais é bem mais complexa do que supõem as visões mecanicista e idealista, posto que a primeira empobrece a noção da historicidade do conhecimento, e a segunda mistifica o próprio conhecimento.

\section{CONSIDERAÇÕES FINAIS}

Igualmente, avulta as ricas possibilidades de contribuir com a Gestão do Conhecimento, visto que a hermenêutica precede a operacionalização.

A título de conceito operacional, a Gestão do Conhecimento, em consonância com o magistério de Nonaka e Takeuchi (1997), consiste em explicitar o conhecimento emanado da experiência pessoal.

Esta disciplina gera a criação de criação de mecanismos e procedimentos dedicados a estimular a formação de competências e prover a ampliação generalizada do conhecimento relevante em todos os níveis desejados.

De acordo com Figueiredo (2005), a gestão do conhecimento visa a que as organizações equacionem as melhores maneiras de produzir e mobilizar conhecimento individual, transformandoo em conhecimento organizacional. 
Destarte, fortalecendo processos produtivos, melhorando serviços e produtos oferecidos, tornando o compartilhamento de informações mais dinâmico, na velocidade que a organização necessita, alavancando a inovação e a inteligência competitiva, viabilizando-a a operar de modo otimizado, de forma a encurtar o tempo de desenvolvimento de produtos e de respostas aos entornos e à sociedade em geral.

Com isto, a Gestão do Conhecimento efetua melhoria no atendimento aos clientes e o relacionamento com os agentes stakeholder, aumenta a autonomia dos empregados, atrai e retém os melhores colaboradores, facilita a obtenção da informação e a criação de novos conhecimentos.

De seu vértice, Ponchirolli (2005, p. 78) assim conceitua a Gestão do Conhecimento:

Ela trata da prática de agregar valor à informação e distribuí-la, tendo como tema central o aproveitamento dos recursos existentes na empresa. Enfatiza o capital humano, proporcionando a criação de novas idéias e processo, identificando, captando, distribuindo, compartilhando e alavancando o conhecimento. Implica, portanto, a adoção de práticas gerenciais compatíveis com os processos de criação e aprendizado individual e organizacional.

Por fim, incentiva a aprendizagem, localiza e utilizar o potencial intelectual dos funcionários, acelera o processo da aprendizagem em todos os níveis da empresa, explorar o conhecimento humano, as habilidades e o potencial dos funcionários, conceber e otimizar processos eficazes e alavancar melhores práticas, utilizar a inteligência dispersa na organização, adotar decisões de melhor qualidade, cria novos processos organizacionais e promove a integração das ilhas do conhecimento existentes na organização. 


\section{REFERÊNCIAS}

ADOLFO, Luiz Gonzaga Silva. Globalização e estado contemporâneo. São Paulo: Memória Jurídica, 2001.

BARBOSA, Alexandre de Freitas. O mundo globalizado. São Paulo: Contexto, 2001.

BERTELLI, Antônio R; PALMEIRA, Moacir G. S.; VELHO, Otávio Guilherme. Sociologia do conhecimento. 2 ed. Rio de Janeiro: Zahar, 1974.

CRESPI, Franco; FORNARI, Fabrizio. Introdução à sociologia do conhecimento. Bauru, SP: EDUSC, 2000.

FIGUEIREDO, Saulo Porfírio. Gestão do conhecimento: estratégias competitivas para a criação e mobilização do conhecimento na empresa: descubra como alavancar e multiplicar o capital intelectual e o conhecimento da organização. Rio de Janeiro: Qualitymark, 2005.

INKELES, Alex. O que é sociologia?: uma introdução à disciplina e à profissão. 3 ed. São Paulo: Pioneira, 1980.

LALLEMENT, Michel. História das idéias sociológicas: de Parsons aos contemporâneos. Petrópolis, RJ: Vozes, 2004.

MACHADO NETO, Antônio Luís. Formação e temática da sociologia do conhecimento. São Paulo: Convívio, 1979.

MORETTO, Vasco Pedro. Construtivismo: a produção do conhecimento em aula. 4. ed. Rio de Janeiro: DP\&A, 2003.

NONAKA, I; TAKEUCHI, H. Criação de conhecimento na empresa: como as empresas japonesas geram a dinâmica da inovação. Rio de Janeiro: Campus, 1997.

PONCHIROLLI, Osmar. Capital humano: sua importância na gestão estratégica do conhecimento. Curitiba: Juruá, 2005.

SANTOS, José Vicente dos; GUGLIANO, Alfredo Alejandro. A sociologia para o século XXI. Pelotas: Educat, 1999.

SOUTO, Cláudio. Teoria sociológica geral. Porto Alegre: Globo, 1974.

SOBRAL, Fernanda da Fonseca; PORTO, Maria Stella Grossi; (Orgs.). A Contemporeidade Brasileira: dilemas e desafios pra a imaginação sociológica. Santa Cruz do Sul: Edunisc, 2001. 